\title{
Examining the Effects of Aesthetic Education Program on Aesthetic Judgment Development of Five-Year-Old Children
}

\author{
Esra ÜNLÜER ${ }^{1}$ \\ Rengin ZEMBAT ${ }^{2}$ \\ 'Department of Preschool Education, Kocaeli University, Kocaeli, Turkey \\ Email:esra.unluer@kocaeli.edu.tr.Tel: +902623032443 \\ ${ }^{2}$ Department of Preschool Education, Maltepe University, İstanbul, Turkey
}

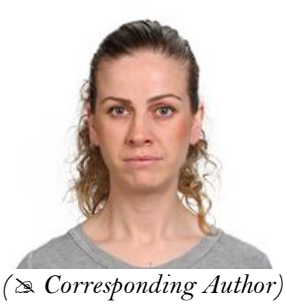

Abstract

This study aims to identify the effectiveness of the Aesthetic Education Program on aesthetic judgment development of the five year old children. The pre-test and post-test control group experimental design was applied throughout the study. The group matching technique was employed in constitution of the study groups. Participants of the study consist of 36 five-year-old children attending at the Kocaeli University Application Kindergarden at the 2016-2017 academic year. Participants were assigned to experimental and control groups equally. Experimental group was taught through Aesthetic Education Program in twice a week for 10 weeks together with their curriculum. Participants in the control group thought through national early childhood curriculum. In the study THPC Aesthetic Judgment Scale which was developed by Taylor and Helmstadter (1971) adapted Turkish culture and validated by Acer (2006) validity and reliability. The validity and reliability of THPC Aesthetic Judgment Scale for five years olds children were by researcher. In statistical data analysis, Mann Whitney U-Test and Wilcoxon Signed Rank Test were used. The results indicated that Aesthetic Education Program effects positively five-years old children's aesthetic judgment development.

Keywords: Aesthetic, Aesthetic judgment, Aesthetic education program, Aesthetic experience, Preschool education, Art

Citation | Esra ÜNLÜER; Rengin ZEMBAT (2019). Examining the Effects of Aesthetic Education Program on Aesthetic Judgment Development of Five-Year-Old Children. Asian Journal of Education and Training, 5(1): 44-49.

\section{History:}

Received: 28 September 2018

Revised: 26 October 2018

Accepted: 30 November 2018

Published: 21 December 2018

Licensed: This work is licensed under a Creative Commons

Attribution 3.0 License (cc)

Publisher: Asian Online Journal Publishing Group
Contribution/Acknowledgement: This paper was written from the first author's complete doctoral dissertation under supervision of Professor Rengin Zembat at Marmara University, Turkey

Funding: This study received no specific financial support.

Competing Interests: The authors declare that they have no conflict of interests.

Transparency: The authors confirm that the manuscript is an honest, accurate, and transparent account of the study was reported; that no vital features of the study have been omitted; and that any discrepancies from the study as planned have been explained.

Ethical: This study follows all ethical practices during writing.

\section{Contents}

1. Introduction

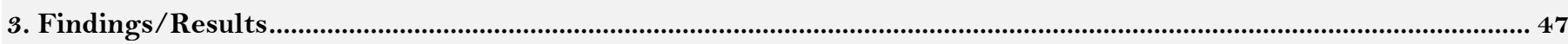

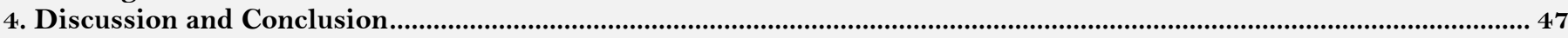

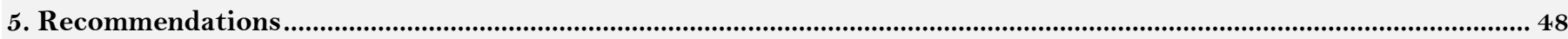

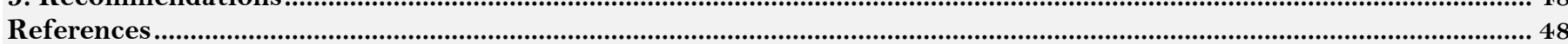




\section{Introduction}

The term aesthetics was first used by German philosopher Alexander Baumgarten in 1744, in the sense of beauty science. The word aesthetics comes from the word aesthetikos, which is associated with the Greek perception of sense (Crawford, 1991). Although there is no definition to fully meet the concept of aesthetics, it is basic form of a person's reaction such as the art, movement, music and trying to find the best in life and love, being aware of the natural beauty in the nature and around us, and knowing the value of them, to see and enjoy the beauty, affective and cognitive sensation and feeling. Aesthetics is at the center of our daily life, because the colours, flavours and sensations in our environment contribute to the development of our aesthetic awareness (Fox and Schirrmacher, 2014).

The aesthetic experience begins with birth and is gradually shaped by culture. The early stages of aesthetic development are universal (Parsons, 1987). Cottrell (1987) states that the artistic sense in children is composed of five developmental stages. First stage (from kindergarten to 3rd grade): Children perceive and discover aesthetic features. Perceptual discovery of aesthetic features involves the development of children's perceptual skills and they become aware of cultural traditions with the help of the world of art. Second stage (4th-6th grade): Includes the development of perceptual skills. Third stage (7th-9th grade): The sense of art history develops. Fourth stage (10th-11th grade): Child develops sample evaluation criteria. Final stage (Grade 12): Child Performs critical analysis (Wee, 2009). Education of aesthetics, such as art, music, cannot be considered as a discipline in itself, but in fact, education of aesthetics covers all fields of art. Education of aesthetics involves all aesthetic phenomena. This phenomenon includes aesthetic experiences, the production process of aesthetic products (object and situation) and the historical and cultural traditions created (Madeja, 1976).

An educational program should support the development of aesthetics with all its aspects. In order to provide this support, it is important that the training program consists of integrated activities. When it comes to supporting the development of aesthetics in children, only art-related activities such as painting or music in the education program come to mind. In fact, it should be known that aesthetic elements can be included in the training process in all activities. Arrangement of the learning environment in such a way as to improve the aesthetic sense of children shall also contribute to the integration of aesthetic education (Feeney and Moravcik, 1986). The preschool education program, which was put into practice in Turkey in 2013, has two achievements and six indicators related to aesthetic development. All activities can be used to promote the development of aesthetics in pre-school education program (Turkish Ministry of Education, 2013). Through education of aesthetics, the child tends to see the details, to pay attention to the views that he has not noticed before. Education of Aesthetics is generally seen as the descriptor of art if it is taken into the art branch. It allows the children to indulge in through their characteristics such as the colors, lines, shapes, formations, proportion, harmony and symmetry in the work of art, and it reveals the spiritual forces inherent in children (Gültekin, 2011).

Some art experts think that young children do not have the maturity to perform aesthetic reactions. Therefore, they think that aesthetics is not a suitable subject at an early age. However, early childhood educators know that children love the beautiful, the nature, and they like to create, look and talk about art (Feeney and Moravcik, 1986). Taking all these into consideration, it is emphasized that any activity daily planned in 2013 the Turkey preschool education program should be of the quality to promote the creativity and aesthetic skills. However, it is thought that the activities supporting the aesthetic skills are insufficient in both the examples of the activities of the teachers and the resource books that the teachers benefit from. As a result of the literature review, it has been observed that the studies related to this subject are insufficient.

\subsection{Purpose}

The aim of this study is to reveal the effects of Aesthetic Education Program applied on five-year-old children on the development of their aesthetic judgement. In accordance with this main objective, it is aimed to make a difference with an application to be carried out without disrupting the current program flow the Aesthetic Education Program to be prepared by the researcher.

Based on this purpose, this research study aims to find out answer the questions below;

1. In terms of the effect of the Aesthetic Education Program on the Aesthetic Judgement scores of the experimental and control groups;

1.1. Is there a significant difference between the experimental group aesthetic judgement pre-test and post-test scores?

1.2. Is there a significant difference between the control group aesthetic judgement pre-test and post-test scores?

1.3. Is there a significant difference between the post-test scores of the experimental and control groups?

\section{Method}

\subsection{Study model}

In the research, experimental patterns with pretest-posttest control group was used. The experimental pattern is the model in which the data to be observed are produced and certainly compared with the aim of trying to determine cause-effect relationships (Karasar, 2003). The pretest-posttest control group pattern requires the measurement of the participants in relation to the dependent variable before and after the experimental procedure (Büyüköztürk, 2010). In the pretest-posttest control group model, there are two groups formed by random method. One of these is called experimental and the other one is called control group. Measurements are performed on both groups before and after the experiment (Karasar, 2003). 
Table-1. Experimental Research Design

\begin{tabular}{l|l|l|l}
\hline & Pretest & Program & Posttest \\
\hline $\begin{array}{l}\text { Experimental } \\
\text { Group }\end{array}$ & $\begin{array}{l}\text { Taylor-Helmstadter Pair } \\
\text { Comparison Scale of }\end{array}$ & Aesthetic Education Program & $\begin{array}{l}\text { Taylor-Helmstadter Pair } \\
\text { Comparison Scale of } \\
\text { Aesthetic Judgment }\end{array}$ \\
\cline { 3 - 4 } Control Group & Aesthetic Judgment & $\begin{array}{l}\text { Instruction based on current } \\
\text { curriculum }\end{array}$ & \\
\hline
\end{tabular}

Experimental group was taught through Aesthetic Education Program in twice a week for 10 weeks together with their curriculum. The control group continued to study their preschool curriculum. Aesthetic Education Program was presented below.

\begin{tabular}{|c|c|}
\hline Weeks & Activities \\
\hline \multirow{2}{*}{1.} & "Children's Games" Pieter Bruegel \\
\hline & Shared book reading \\
\hline \multirow{2}{*}{2.} & "Shoes" review \\
\hline & Shared book reading \\
\hline \multirow{2}{*}{3.} & "Happy Children” photo taken by Ara Güler \\
\hline & Museum visit \\
\hline \multirow{2}{*}{4.} & Light table activities \\
\hline & "Forest trip" Nature review \\
\hline \multirow{2}{*}{5.} & “The Weeping Woman” Pablo Picasso \\
\hline & Museum visit \\
\hline \multirow{2}{*}{6.} & “The Starry Night” Vincent van Gogh \\
\hline & Shadow puppet \\
\hline \multirow{2}{*}{7.} & “Cups" review \\
\hline & "Clouds" Nature review \\
\hline \multirow{2}{*}{8.} & Museum visit \\
\hline & Shadows \\
\hline \multirow{2}{*}{9.} & Optical illusion \\
\hline & Painting exhibition visit \\
\hline \multirow{2}{*}{10.} & Installation Art \\
\hline & Virtual museum visit \\
\hline
\end{tabular}

\subsection{Sampling}

The study group of this study consisted of five-year-old children attending Kocaeli University Kocaeli University Application Kindergarden in 2016-2017 school year. In this study, group matching technique method was used to create study groups The reason why Kocaeli University Application Kindergarden was chosen for the study is that the variables of children (physical conditions of the school, socio-cultural level of the family) are similar, and there are two classes in five-age group and maximum 20 children in each class, and it was permitted to carry out the study, which would take 1-3 hours on two days of the week, a vehicle could be provided for planned trips, and the school administration and teachers have a positive approach and willingness for the study.

Tablo-3. The results of the pre-test scores of THPC Aesthetic Judgment Scale for experimental and control group

\begin{tabular}{|c|c|c|c|c|c|c|c|}
\hline Scale & Group & $\mathbf{N}$ & Mean rank & Sum of ranks & $\mathbf{U}$ & $\mathbf{Z}$ & $\mathbf{P}$ \\
\hline \multirow{3}{*}{$\begin{array}{l}\text { Aesthetic } \\
\text { Judgement } \\
\text { Scale }\end{array}$} & Experimental & 18 & 321.50 & 17.86 & \multirow{3}{*}{150.50} & \multirow{3}{*}{-3.73} & \multirow{3}{*}{.709} \\
\hline & Control & 18 & 344.50 & 19.14 & & & \\
\hline & & 36 & & & & & \\
\hline
\end{tabular}

As shown in Table 3, results of the Mann Whitney-U test reveals that there is not any significant difference between the THPC Aesthetic Judgment Scale pretest scores of experimental and control groups. According to this result, it can be said that the aesthetic judgement levels of the two groups are equal before the application.

\subsection{Data Collection Tools}

\subsubsection{Taylor-Helmstadter Pair Comparison Scale of Aesthetic Judgment (THPC)}

The THPC Aesthetic Judgement Scale is an assessment tool developed by Taylor and Helmstadter (1971) in order to measure aesthetic judgement in children aged four and over based on the Gestalt Theory. The scale consists of 38 pairs of images among which various images with or without artistic value like furniture design; sculpture, painting and home appliances are contained. The applied instrument one-to-one takes 15-20 minutes. It was adapted by Acer (2006) to Turkish Culture for 6-year-old children. As a result of the validity studies conducted by Acer (2006) pairs of images were reduced to 16 pairs. The reliability and validity study was conducted for 5 years old children by the researcher. According to the results of this study, the scale was found to be valid (CVI of 0.86 and $\mathrm{CVI} \geq \mathrm{CVO}$ ) and reliable (Cronbah's alpha of 0.66) (Unluer and Zembat, 2017).

\subsection{Analyzing of Data}

In order to determine the tests to be used in the analysis of the data, it has been tested whether the data is normally distributed or not. As a result of hypothesis testing, it was found that the data did not meet the normality hypothesis. Therefore, nonparametic tests were performed. 


\begin{tabular}{|c|c|c|c|c|c|c|}
\hline \multirow{2}{*}{$\begin{array}{l}\text { Aesthetic Judgement } \\
\text { Scale }\end{array}$} & \multicolumn{3}{|c|}{ Kolmogorov-Smirnov } & \multicolumn{3}{|c|}{ Shapiro Wilk W } \\
\hline & Statistic & df & $\mathbf{P}$ & Statistic & df & $\mathbf{P}$ \\
\hline & .173 & 36 & .008 & .935 & 36 & .037 \\
\hline
\end{tabular}

The data obtained from the study were evaluated by using "SPSS 18.0" statistical package program. In this context, the following statistical techniques were implemented. The frequency and percentage values of the demographic characteristics of the study group were determined. Mann Whitney U-Test (MWU) was used to compare the pretest-posttest scores of the experimental and control groups. The Wilcoxon Signed Ranks test was used to compare the pre and post-tests of the experimental and control groups.

\section{Findings/Results}

Findings of this study were presented below.

Table-5. The results of the pre-test and post-test scores of THPC Aesthetic Judgment Scale for experimental group

\begin{tabular}{|c|c|c|c|c|c|c|}
\hline Scale & Group & $\mathbf{N}$ & Mean rank & Sum of ranks & $\mathbf{Z}$ & $\mathbf{P}$ \\
\hline \multirow{4}{*}{ Aesthetic Judgement Scale } & Negative ranks & 0 & .00 & .00 & \multirow{4}{*}{$-3.65^{*}$} & \multirow{4}{*}{$.00 * *$} \\
\hline & Pozitif ranks & 17 & 9.0 & 153.00 & & \\
\hline & Ties & 1 & & & & \\
\hline & Total & 18 & & & & \\
\hline
\end{tabular}

$$
\begin{aligned}
& \text { *Ba } \mathrm{p}<.01 \\
& \text { Based on }
\end{aligned}
$$

As shown in Table 5, results of the Wilcoxon Signed Ranks Test reveals that there is significant difference between the THPC Aesthetic Judgment Scale pretest and posttest scores of experimental group ( $\mathrm{z}=3.65$; $\mathrm{p}<.01)$.Taking mean rank and sums of the difference scores into consideration, it is given that the observed difference is in favour of the positive ranks, in other words, the post-tests. These findings, it can be concluded that the Aesthetic Education Program effected positively the development of aesthetic judgement of the five-year old children.

\begin{tabular}{|c|c|c|c|c|c|c|}
\hline Scale & Group & $\mathbf{N}$ & Mean rank & Sum of ranks & $\mathbf{Z}$ & $\mathbf{P}$ \\
\hline \multirow{4}{*}{$\begin{array}{l}\text { Aesthetic } \\
\text { Judgement Scale }\end{array}$} & Negative ranks & $\mathrm{O}$ & .00 & .00 & \multirow{4}{*}{$-1.732 *$} & \multirow{4}{*}{$.08 * *$} \\
\hline & Pozitif ranks & 3 & 2.00 & 6.00 & & \\
\hline & Ties & 15 & & & & \\
\hline & Total & 18 & & & & \\
\hline
\end{tabular}

As shown in Table 6, results of the Wilcoxon Signed Ranks Test reveals that there is not any significant difference between the THPC Aesthetic Judgment Scale pretest and posttest scores of control group $(\mathrm{z}=1.732$; $\mathrm{p}>$.05). According to this result, it can be said that MEB 2013 pre-school education program did not contribute to the development of aesthetic judgement skills of children.

\begin{tabular}{|c|c|c|c|c|c|c|c|}
\hline Scale & Group & $\mathbf{N}$ & Mean rank & Sum of ranks & $\mathbf{U}$ & $\mathbf{Z}$ & $\mathbf{P}$ \\
\hline \multirow{3}{*}{$\begin{array}{l}\text { Aesthetic } \\
\text { Judgement } \\
\text { Scale }\end{array}$} & Experimental & 18 & 453.50 & 25.19 & \multirow{3}{*}{41.50} & \multirow{3}{*}{-3.89} & \multirow{3}{*}{$.00^{*}$} \\
\hline & Control & 18 & 212.50 & 11.81 & & & \\
\hline & & 36 & & & & & \\
\hline
\end{tabular}

As shown in Table 7., as a result of the Mann Whitney- $\mathrm{U}$ test reveals that there is statistically significant difference between the scores ( $\mathrm{U}=41.50 ; \mathrm{p}<.01)$ of THPC Aesthetic Judgment Scale in terms of the experimental and control group post-tests. Considering their mean ranks, it can be seen that the difference is in favour of the experimental group. According to the results, the aesthetic judgement skills of the children in the experimental group participating in the Aesthetic Education Program are higher than that of the children in the control group who did not participate in the training. This findings show that the program has a positive effect on children's aesthetic judgement skills.

\section{Discussion and Conclusion}

When the THPC Aesthetic Judgment Scale post-test scores of the experimental and control groups were compared, there was a significant difference in favour of the experimental group. This result shows that the children in the experimental group have higher aesthetic judgement level than the children in the control group and that the applied Aesthetic Education Program effects significantly the development of the aesthetic judgement levels of children. Accordingly, the aesthetic judgement levels of the children in the experimental group participating in the Aesthetic Education Program were higher than the children in the control group who did not participate in the training. The fact that the aesthetic judgement levels of the children attending the Aesthetic Education Program are higher than the ones attending the preschool education program of TME (2013) and not participating in this program is considered to stem from the fundamental principles which constitute the Aesthetic Education Program. The reason why the program has shown the expected development is related with the fundamental principles of the program such as drawing attention of the children by means of activities, organising 
the class atmosphere within the framework of aesthetic principles, giving feedbacks to children and suggesting different educational atmosphere.

When the results of the study related to the aesthetic judgement level are examined, it can be seen that similar results have been reached with various studies conducted in Turkey and abroad (Taylor, 1971; Eckhoff, 2006; Davun, 2009; Özalp, 2012; Kocamanoğlu and Acer, 2015).

In the study conducted by Taylor (1971) one of the researchers who developed the scale, the effect of the aesthetic education given with artistic products on the perception development and aesthetic judgement levels of the 4-5-year-old children who were attending pre-school education were examined. THPC Aesthetic Judgment Scale, which he developed with Helmstadler, was applied and it was determined whether the environment and education had an effect on aesthetic preference and aesthetic development. According to the results of the study, it was determined that the aesthetic preferences of the students in the experimental group were higher than the other group. The findings of this study coincide with the findings of our study.

Eckhoff (2006) studied the effect of museum education on the aesthetic appreciation of children. In his study, he worked with 63 children between the ages of four and eleven, and he found that the children who were actively experienced art could assess the artworks. This result is consistent with the results of our study. In both programs, there are stages such as examination, interpretation and recreation of artworks by children, which enables them to actively participate in the aesthetic process from the very first stage and develop their aesthetic judgment skills. Results of this study show similarities in terms of developing children's aesthetic skills since museum visits were included in the both aesthetic education program. Results of both studies imply the importance and contribution of museums on aesthetic skills of children.

According to the definition of postmodern art, story book covers, which are part of a visual and popular culture, are accepted as an artwork (Freedman, 2003). Illustrated books offer excellent opportunities for aesthetic experiences (Nodelman, 1988). The aesthetic experiences of children were tried to be increased with the illustrated story books included in the prepared Aesthetic Education Program. (Chou and Cheng, 2015) showed that reading aesthetic books by sharing with their families improved their aesthetic skills. In addition, Justice et al. (2009) found that books read in the classroom increased the aesthetic experience of children. These studies are in parallel with the findings of our research.

Acer and Ömeroðlu (2008) conducted a similar experimental study with 6 year old children by implementing a different aesthetic education program. However, the aforementioned study found out that aesthetic education program did not show any important effect on the development of children's aesthetic judgment. The reason for the discrepancy between the results of this study and their might be age of the participants and the difference of the applied programs.

\section{Recommendations}

The Aesthetic Education Program can be compared with the findings obtained by applying it in different economic, social and cultural environments.

- A larger-scale study including children of different ages can be achieved, and the results can be broadened to a wider audience.

- The assessment of the impacts of the Aesthetic Education Program can be strengthened to a certain extent through feedback from children, as well as feedback from families and teachers and from an independent observer. At the same time, the effectiveness of the program can be measured using different measurement tools.

- The study group is limited to 36 children. In the future, research may be repeated with larger study groups and the ones which vary in terms of socio-economic levels.

\section{References}

Acer, D., 2006. Examining the effect of aesthetic education on aesthetic judgment development of 6 year old children attending Kindergarten. Unpublished Doctoral Dissertation. Gazi University, Institute of Educational Sciences, Department of Child Development and Education.

Acer, D. and E. Ömeroðlu, 2008. A study on the effect of aesthetic education on the development of aesthetic judgment of six-year-old children. Early Childhood Education Journal, 35(4): 335-342. Available at: https://doi.org/10.1007/s 10643-007-0193-4.

Büyüköztürk, Ş., 2010. Manual of data analysis for social sciences. Ankara: Pegem Academy.

Chou, M.-J. and J.-C. Cheng, 2015. Parent-child aesthetic shared reading with young children. Universal Journal of Educational Research, 3(11): 871-876. Available at: https://doi.org/10.13189/ujer.2015.031113.

Cottrell, J., 1987. Creative drama in the classroom, grades 4-6: Teacher's resource book for theatre arts. Lincolnwood, IL: National Textbook Company

Crawford, D.W., 1991. The questions of aesthetics (s, 18-30). R.A.Smith ve A. Simpson (Ed.), Aesthetic and art education Urbana ve Chicago. USA: University of Illinois Press. pp: 18-31

Davun, B., 2009. The effect of arts education supported by activities in pre-school period on the aesthetic taste levels of children (social services child protection agency example). Unpublished PhD Thesis. Gazi University Institute of Educational Sciences, Ankara.

Eckhoff, A., 2006. Influences on children's aesthetic responses: The role of prior knowledge, contexts, and social experiences during interactions with the visual arts. Doctoral Dissertation. University of Colorado, Boulder.

Feeney, S. and E. Moravcik, 1986. A thing of beauty: Aesthetic development in young children. Young Children, 42(6): 6-15.

Fox, J.E. and R. Schirrmacher, 2014. Aesthetic. Translated by M. Can Yasar N, Aral and Gokhan Duman (Translated Ed.) Development of art and creativity in children. Ankara: Nobel Publishing.

Freedman, K., 2003. Teaching visual culture: Curriculum, aesthetics, and the social life of art. New York and London: Teachers College Press, Columbia University.

Gültekin, T., 2011. Children and communication in the process of development of aesthetic values in art education. Academic Review Journal(24): 32-39

Justice, L.M., J.N. Kaderavek, X. Fan, A. Sofka and A. Hunt, 2009. Accelerating preschoolers' early literacy development through classroombased teacher-child storybook reading and explicit print referencing. Language, Speech, and Hearing Services in Schools, 40(1): 67-85. Available at: https://doi.org/10.1044/0161-1461(2008/07-0098.

Karasar, N., 2003. Scientific research method: Concepts, principles, methods. Ankara: Nobel Publication Distribution.

Kocamanoğlu, D.Ö. and D. Acer, 2015. Examining children's art products and determining their aesthetic judgment in a preschool classroom where learning centers were used. Journal of Education(7): 1-16.

Madeja, S.S., 1976. The CEMREL aesthetic education program: A Report. Urbana Chicago: University of Illinois Press. National Association for Young Children, September. 
Nodelman, P., 1988. Words about pictures: The narrative art of children's picture books. Athens, GA: University of Georgia Press. Özalp, H.K., 2012. Case study based on the application of the art in the 5-6 year old art activities. Idil Magazine, 1(5): 132-147.

Parsons, M.J., 1987. How we understand art. New York: Cambridge University.

Taylor, A.B. and G.C. Helmstadter, 1971. A preliminary pair comparison test for measuring aesthetic judgment in young children. Paper Presented at the Annual Meeting of the American Educational Research Association, New York, NY. pp: 4-7.

Taylor, A.P., 1971. The effects of selected stimuli on the art products, concept formation and aesthetic judgmental decisions of four and five year old children. Doctoral Dissertation, Arizona State University, USA.

Turkish Ministry of Education, 2013. Pre-school education program (for 36-72 Months Old Children). Ankara: Turkish Ministry of Education.

Unluer, E. and R. Zembat, 2017. Taylor-helmstadter double comparative aesthetics scale (THPC) validity and reliability study. Electronic Turkish Studies, 12(18): 687-696.

Wee, S.J., 2009. Drama education curriculum by drama specialist in early childhood education. Doctoral Dissertation, Urbana: Illinois University. 